\title{
Effect of Hygrothermal Aging and Surface Treatment on the Dynamic Mechanical Behavior of Flax Fiber Reinforced Composites
}

\author{
Xiaomeng Wang and Michal Petrů * \\ Institute for Nanomaterials, Advanced Technologies and Innovation, Technical University of Liberec, \\ Studentska 2, 46117 Liberec, Czech Republic \\ * Correspondence: michal.petru@tul.cz
}

Received: 28 June 2019; Accepted: 21 July 2019; Published: 25 July 2019

\begin{abstract}
The recent developments of FRP (fiber reinforced polymer) are towards the growth and usage of natural FRP in the field of engineering due to both environmental and economic benefits. Flax fiber is one of the most commonly used natural fibers. One of the critical factors affecting the mechanical behavior of FFRP (flax fiber reinforced polymer) is hygrothermal aging. Some experimental works have been conducted to investigate the effect of hydrothermal aging on static behavior of FFRP. However, fewer efforts have been made to study its damping properties after hydrothermal aging. In this paper, the effect of surface treatment (including alkalization, silanization, acetylation and alkali-silanization) on dynamic mechanical behavior of FFRP under hygrothermal aging is studied. The results show that water resistance and damping properties of FFRP are improved after surface treatment. The acetylation treated FFRP exhibits excellent damping performance among all treated specimens.
\end{abstract}

Keywords: flax fiber; composite; damping; hygrothermal aging

\section{Introduction}

In recent years, the use of flax fiber as a potential alternative to traditional fiber such as glass fiber and carbon fiber in fiber reinforced polymer (FRP) has gained attention among researchers [1-4]. Compared to glass fiber and carbon fiber, flax fiber presents low density, low cost and easy disposal at end-of-life [5,6]. However, the porous structure of flax fiber leads to high water absorption [7-9]. The interaction between hydrophilic fiber and hydrophobic matrix results in weakening of the fiber/matrix interface, dimensional instability, matrix cracking and degradation of mechanical properties of the flax fiber reinforced polymer (FFRP) [10-13]. Some experimental research has been done to study the effect of moisture on the mechanical behavior of FFRP. Assarar et al. [14] and Mak et al. [15] compared the effect of environmental conditioning on the mechanical properties of FFRP and GFRP (glass fiber reinforced composite). Assarar et al. [14] reported that the saturated weight gain of FFRP is 12 times higher than that of GFRP. The weakening of fiber/matrix interface is the main damage mechanism caused by water aging of the FFRP. Mak et al. [15] found that the residual tensile strength of FFRP subjected to salt solution is higher than GFRP. After being soaked in $3.5 \%$ salt solution at $55{ }^{\circ} \mathrm{C}$ for 300 days, the residual strength of FFRP is $72 \%$ of the reference sample, while the residual strength of GFRP is $61 \%$ of the initial value. Ventura et al. [16], Scida et al. [17] and Thuault et al. [18] studied the effect of hygrothermal aging on the mechanical properties of FFRP. Ventura et al. [16] found that the water uptake of FFRP increases with flax fiber content. For example, when fiber content increases from $0 \%$ to $25 \%$, the saturated moisture content of FFRP increases from $1.1 \%$ to $6.2 \%$. Scida et al. [17] reported that after 38 days of hygrothermal aging with a relative humidity of $90 \%$ at $40{ }^{\circ} \mathrm{C}$, the elastic 
modulus and tensile strength of FFRP decrease by $58 \%$ and $52 \%$, respectively. Thuault et al. [18] found that the hygrothermal aging causes disorganization of the flax microfibrils network and the plasticization of the matrix, which leads to mechanical property degradation of FFRP.

Some recent research shows that the water resistance and mechanical properties of FFRP can be improved by chemical treatments such as alkalization [19,20], acetylation [21,22], and silanization [23,24]. For example, Lin et al. [19], Amiri et al. [20] and Bledzki et al. [21] reported that alkalization and acetylation help to clean the fiber surface by removing waxes, oils, and cuticle, therefore the surface morphology of the fiber surface is rougher which results in better mechanical interlocking at fiber/matrix interface. Georgiopoulos et al. [24] reported that silane works as a waterproof coating and a bridge between the fiber and matrix by introducing covalent bonds between the fiber and matrix. After silane treatment, the fiber/matrix interface strength increases, and the moisture absorption of the FFRP is reduced [25].

Damping is one of the important indicators to measure the dynamic mechanical behavior of structures [26]. However, due to a short history of FFRP in the engineering field, the effect of surface treatment on damping of FFRP under hygrothermal aging condition remains an open question. Duc et al. [27] compared the damping properties of composites with different kinds of fiber (glass fiber, carbon fiber, flax fiber) and matrix (epoxy, polypropylene, polylactide). The results show that the damping properties of flax fiber reinforced epoxy composites are better than carbon and glass fiber reinforced composites at room temperature. Adding unidirectional flax fiber to epoxy resin increases the loss factor of epoxy resin by nearly $100 \%$. Cheour et al. [28] studied the effect of water on the damping of FFRP. The results show that loss factor of FFRP increases with soaking time. Berges et al. [29] reported that after being conditioned at $70{ }^{\circ} \mathrm{C}$ with a relative humidity of $85 \%$ for 2 weeks, a significant decrease of the storage modulus of FFRP is observed. Tayfun et al. [30] studied the effect of surface treatment on short flax fiber reinforced thermoplastic polyurethane composite. The results show that after alkali, permanganate, peroxide and silane treatment, the adhesion between short flax fibers and polyurethane is improved, and the storage modulus and glass transition temperature are increased.

Although some experimental works have been reported on the effect of surface treatment on static behavior of FFRP, research on its damping behavior is still limited. In this work, the effect of surface treatment on the damping of FFRP under hygrothermal aging conditions is studied.

\section{Materials and Methods}

The unidirectional flax fabric (Figure 1a) was supplied by Nanjing Hitech Composite Co., Ltd. Epoxy (Nanjing, China) resin (E 44) and curing agent (C 650) from Nantong Xingchen Synthetic Material Co. (Nantong, China) were used as the matrix. Four kinds of chemical treatments of flax fiber were adopted: alkalization, silanization, acetylation and alkali-silanization. Alkalization is soaking the specimen in $5 \mathrm{wt} \% \mathrm{NaOH}$ solution for $0.5 \mathrm{~h}$ at $25^{\circ} \mathrm{C}$. Silanization is soaking the specimen in $0.1 \mathrm{wt} \%$ silane solution (triethoxy silane) for $1 \mathrm{~h}$ at $25^{\circ} \mathrm{C}$. Alkali-silanization is treating with $\mathrm{NaOH}$ solution first, then washing with distilled water and drying in an oven, then treating with silane solution. Acetylation is soaking the specimen in glacial acetic acid for $2 \mathrm{~h}$ at $30^{\circ} \mathrm{C}$ first, and then treating with acetic anhydride (with $\mathrm{FeCl}_{3}$ as catalyzer) for $1 \mathrm{~h}$ at $50^{\circ} \mathrm{C}$.

After surface treatment, FFRP was laminated using hand layup as shown in Figure 1. The FFRP specimen is composed of approximately $30 \%$ fiber in volume. The dimension of FFRP specimen (Figure 1d) in rectangular form is $50 \mathrm{~mm} \times 10 \mathrm{~mm} \times 1.35 \mathrm{~mm}$. The tests were carried out according to Chinese standards GB/T 2573-2008 [31]. After curing in a laboratory environment $\left(25^{\circ} \mathrm{C}\right)$ for 2 weeks, specimens were dried in an oven at $60{ }^{\circ} \mathrm{C}$ for $24 \mathrm{~h}$, and the initial weight of each specimen was measured. Then the specimens were soaked in distilled water at $60^{\circ} \mathrm{C}$ in a test chamber. Specimens were taken out periodically and weighed to evaluate water absorption.

After 4, 9 and 16 days of hygrothermal aging, the specimens were tested to assess the damping properties. DMS (Dynamic Mechanical Spectrometer) 6100 (Hitachi High-Tech Science Corporation, 
Tokyo, Japan) was adopted as the test device to measure the dynamics properties of FFRP, such as storage modulus, loss modulus and loss factor. FFRP specimens were tested under three-point bending mode at a fixed frequency of $1.0 \mathrm{~Hz}$. And the specimens were heated in an air atmosphere at an increased heating rate of $10{ }^{\circ} \mathrm{C} / \mathrm{min}$. All experimental values were obtained by an average value of three specimens.
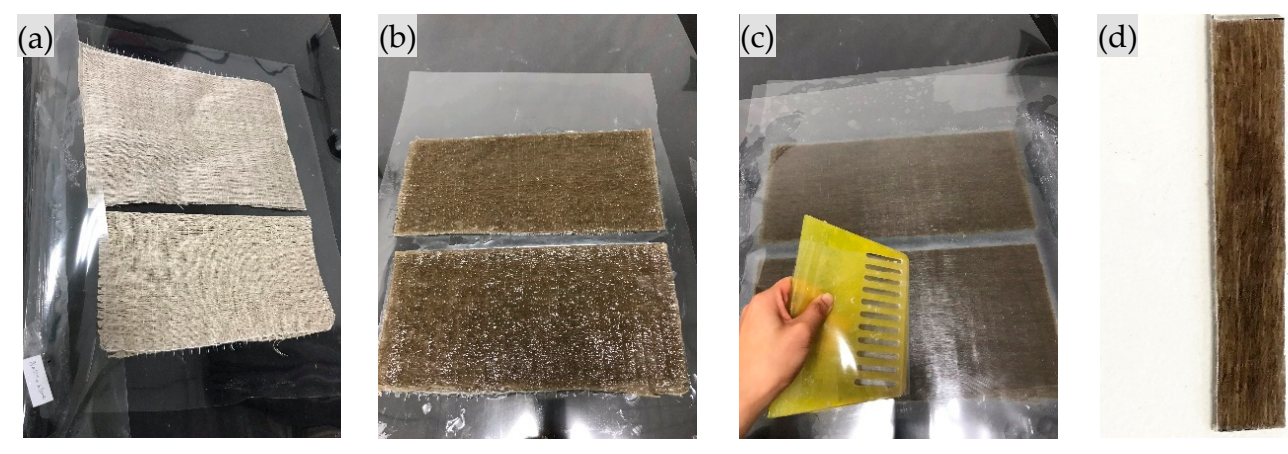

Figure 1. Fabrication of flax fiber reinforced polymer (FFRP) specimen: (a) flax fabric; (b) coating with epoxy; (c) remove bubbles; (d) cut into desired shape.

\section{Test Results}

The water diffusion of the specimen is simplified as a one-dimensional diffusion because the length and width of the specimen are much larger than its thickness. The weight increment percentage $M_{t}$ of FRP in the water absorption test is defined as

$$
M_{t}=\frac{W_{t}-W_{0}}{W_{0}} \times 100 \%
$$

where $W_{0}$ is the initial weight, and $W_{t}$ is the weight after water absorption. Luo et al. [32] and Karbhari et al. [33] reported that the water absorption of FRP follows a Fickian behavior as

$$
\frac{M_{t}}{M_{m}}=\left\{\begin{array}{lr}
\frac{4}{h} \sqrt{\frac{D t}{\pi}}, & \frac{M_{t}}{M_{m}}<0.6 \\
1-\exp \left[-7.3\left[D \frac{t}{h^{2}}\right]^{0.75}\right], & \frac{M_{t}}{M_{m}} \geq 0.6
\end{array}\right.
$$

where $h$ is the specimen thickness, $t$ is the soaking time, and $M_{m}$ is the maximum weight increment percentage. When $\frac{M_{t}}{M_{m}}<0.6$, the diffusivity coefficient $D$ is obtained as

$$
D=\frac{\pi}{t}\left(\frac{h M_{t}}{4 M_{m}}\right)^{2}
$$

Figure 2 and Table 1 show the results obtained from water absorption test.

Table 1. Maximum weight increment percentage $M_{m}$ and diffusion coefficient $D$ of FFRP.

\begin{tabular}{cccccc}
\hline $\begin{array}{c}\text { Surface } \\
\text { Treatment }\end{array}$ & Untreated & Alkalization & Silanization & Acetylation & Alkali-Silanization \\
\hline$M_{m}(\%)$ & 7.75 & 6.40 & 5.60 & 4.48 & 5.27 \\
$D\left(10^{-6} \mathrm{~mm}^{2} / \mathrm{s}\right)$ & 4.19 & 2.93 & 2.36 & 2.21 & 2.27 \\
\hline
\end{tabular}


The dynamic test results of FFRP under different hydrothermal aging are shown in Figure 3. The relationships between the damping properties of FFRP and moisture content are shown in Figures 4 and 5. As shown in Figure 6, a significant decrease in glass transition temperature of FFRP is observed after hygrothermal aging.
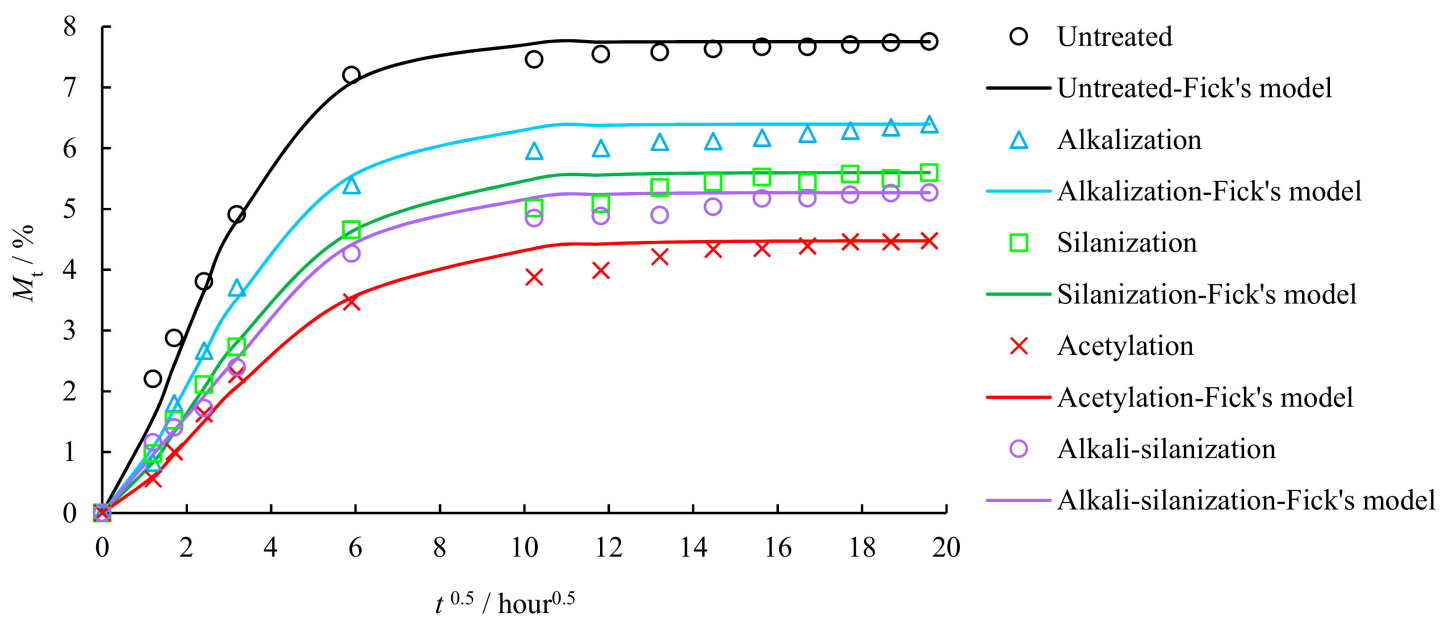

Figure 2. Relative water uptake of FFRP weight increment percentage of FFRP.

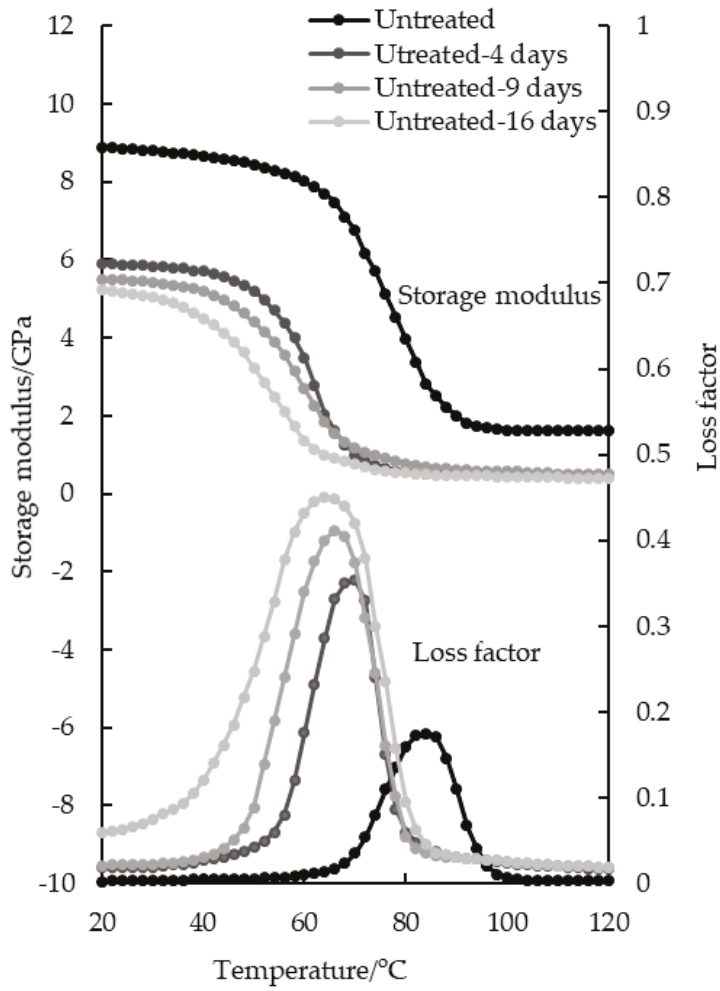

(a) Untreated

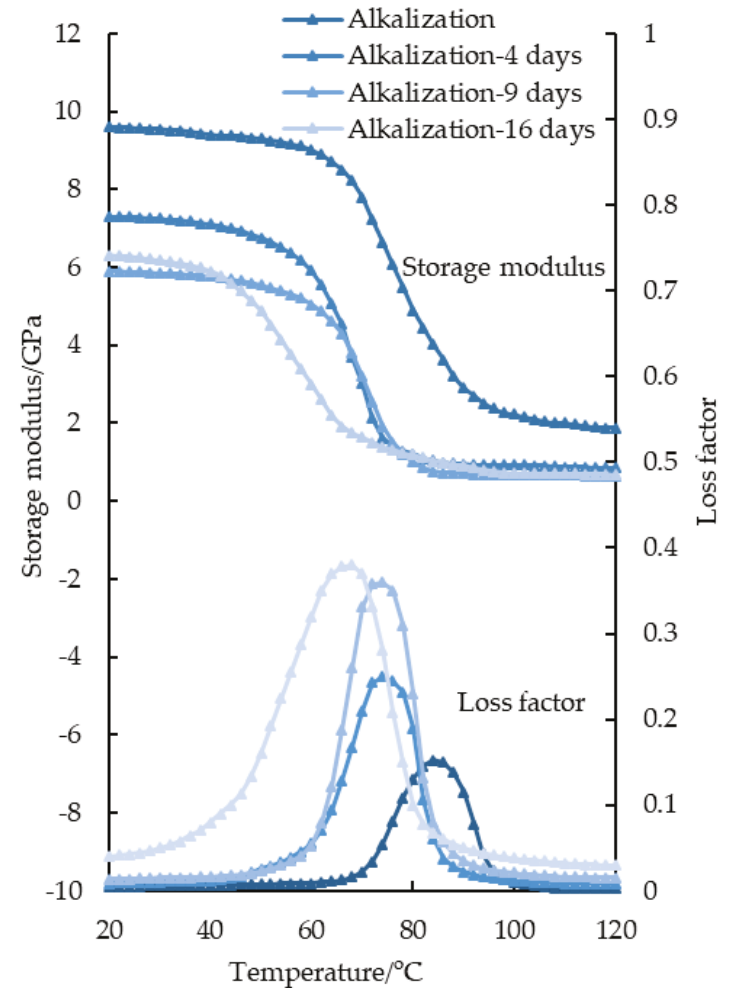

(b) Alkalization

Figure 3. Cont. 


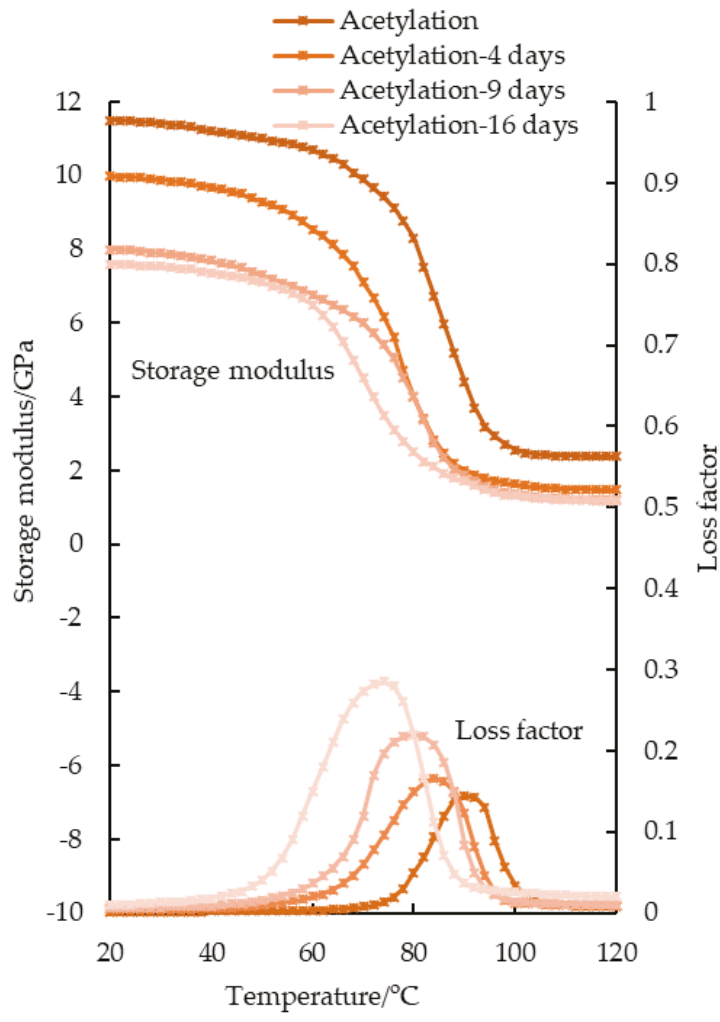

(c) Acetylation

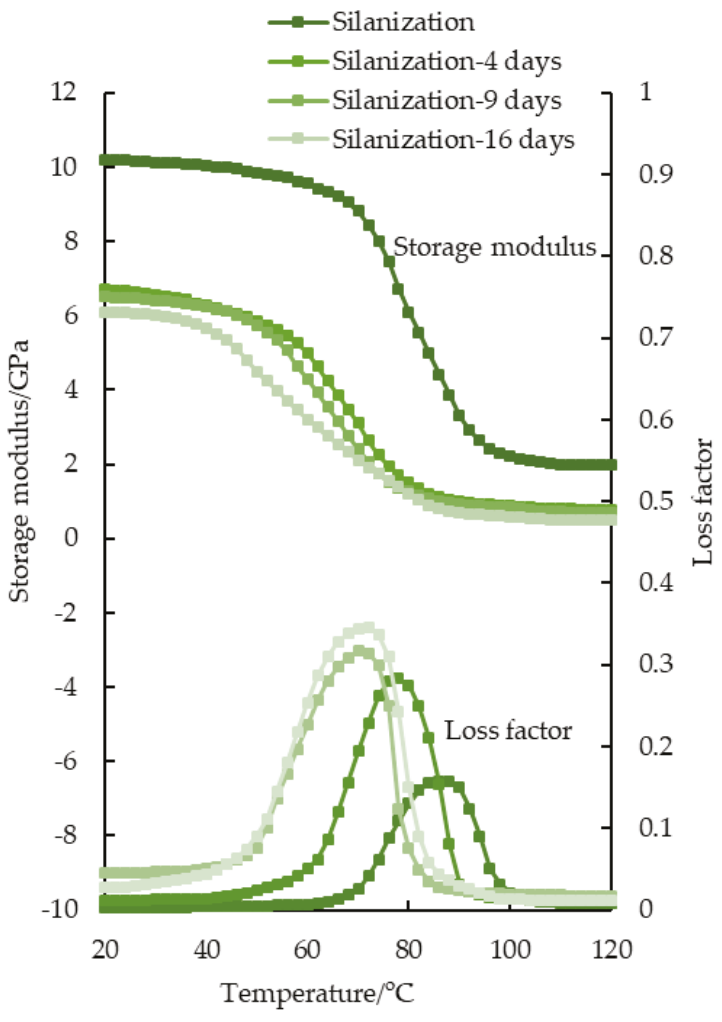

(d) Silanization

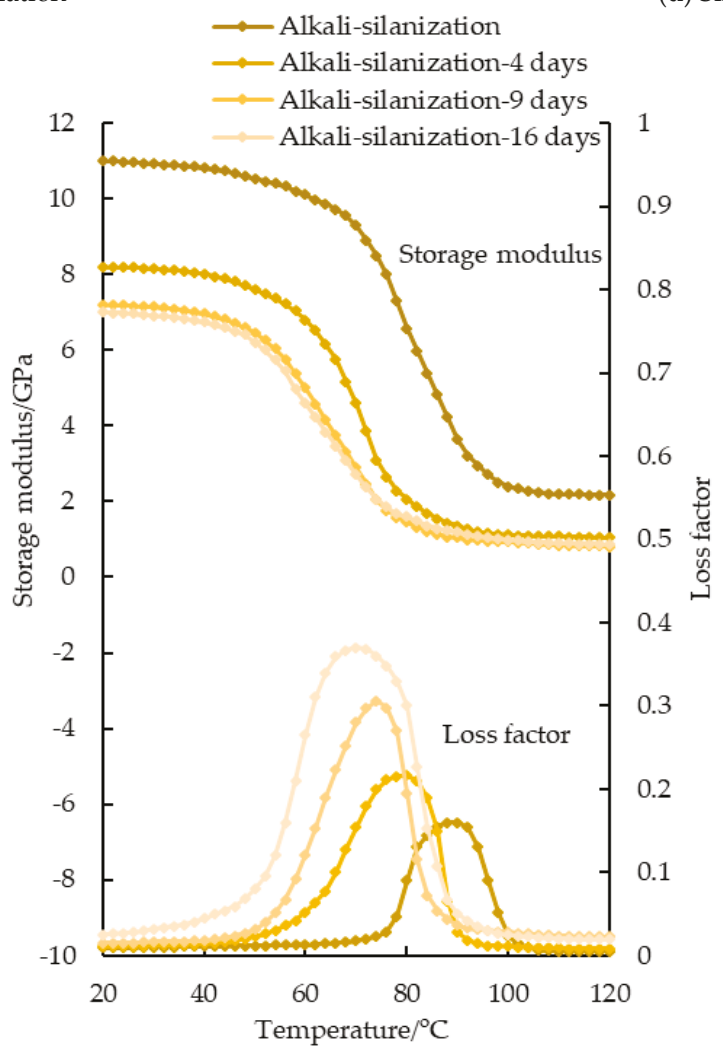

(e) Alkali-silanization

Figure 3. Storage modulus and loss factor of FFRP after hygrothermal aging. 


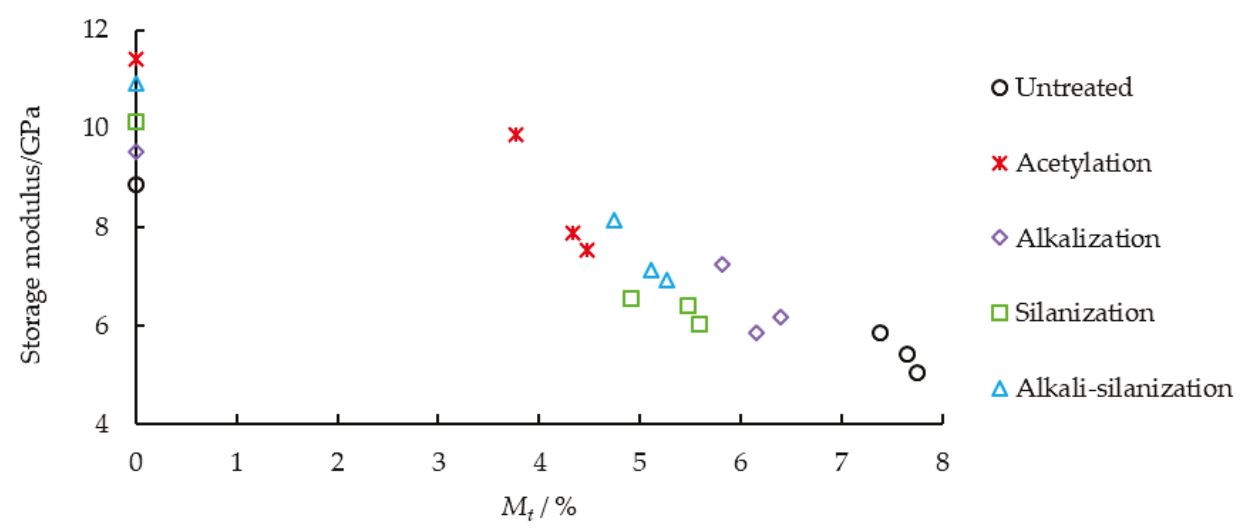

(a) $30{ }^{\circ} \mathrm{C}\left(<T_{g}\right)$

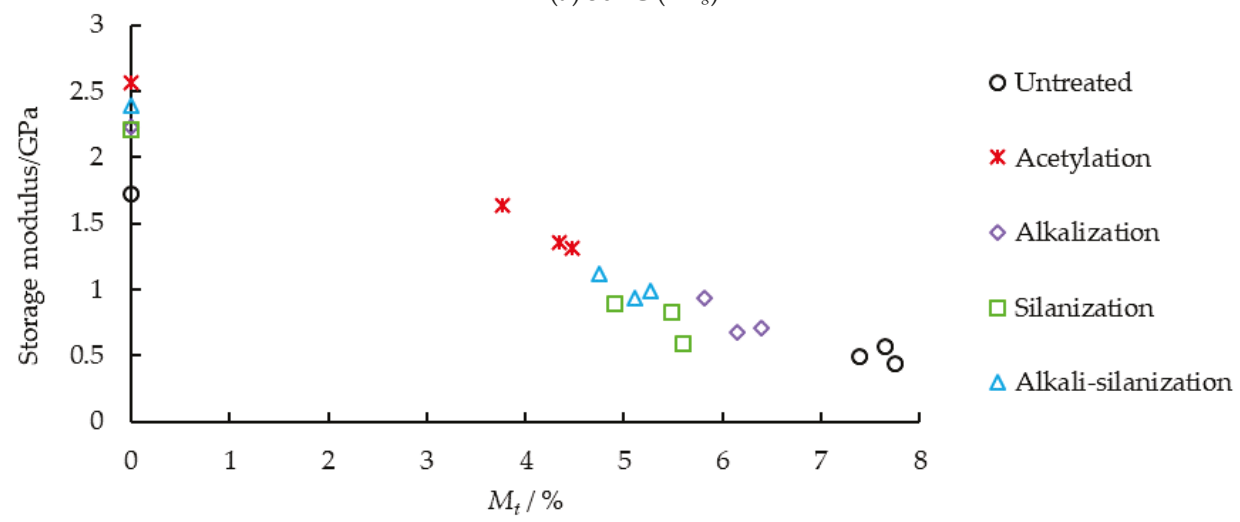

(b) $100{ }^{\circ} \mathrm{C}(>\mathrm{Tg})$

Figure 4. Relationship between storage modulus and moisture content.

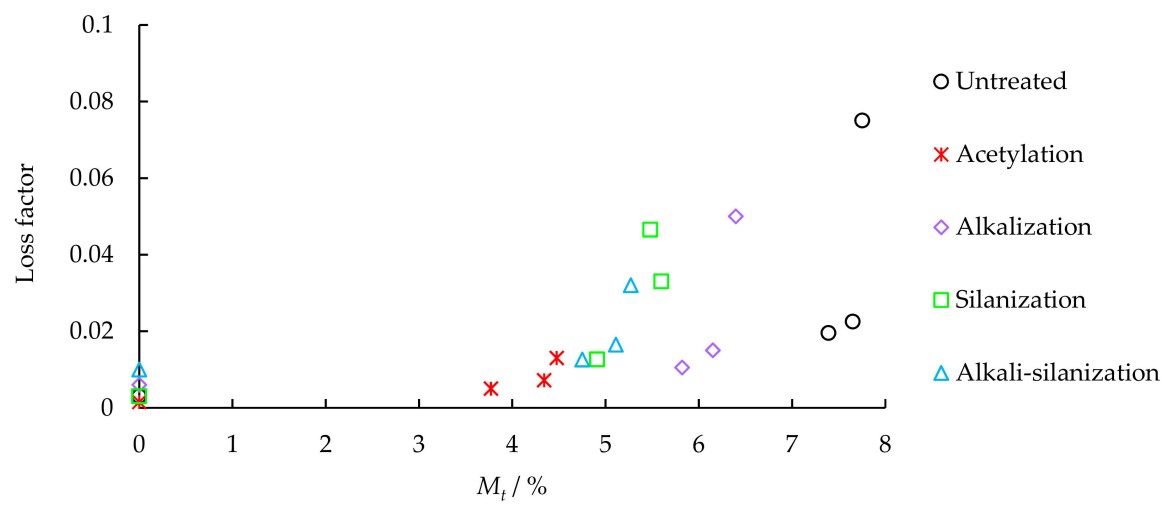

(a) $30{ }^{\circ} \mathrm{C}\left(<T_{8}\right)$

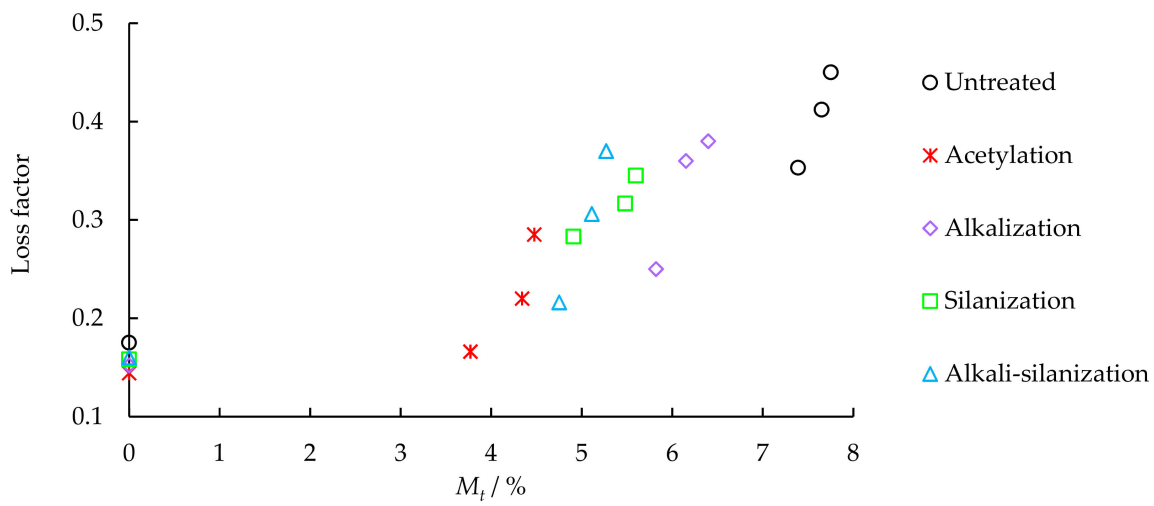

(b) Peak value of loss factor $\left(=T_{8}\right)$

Figure 5. Relationship between loss factor and moisture content. 


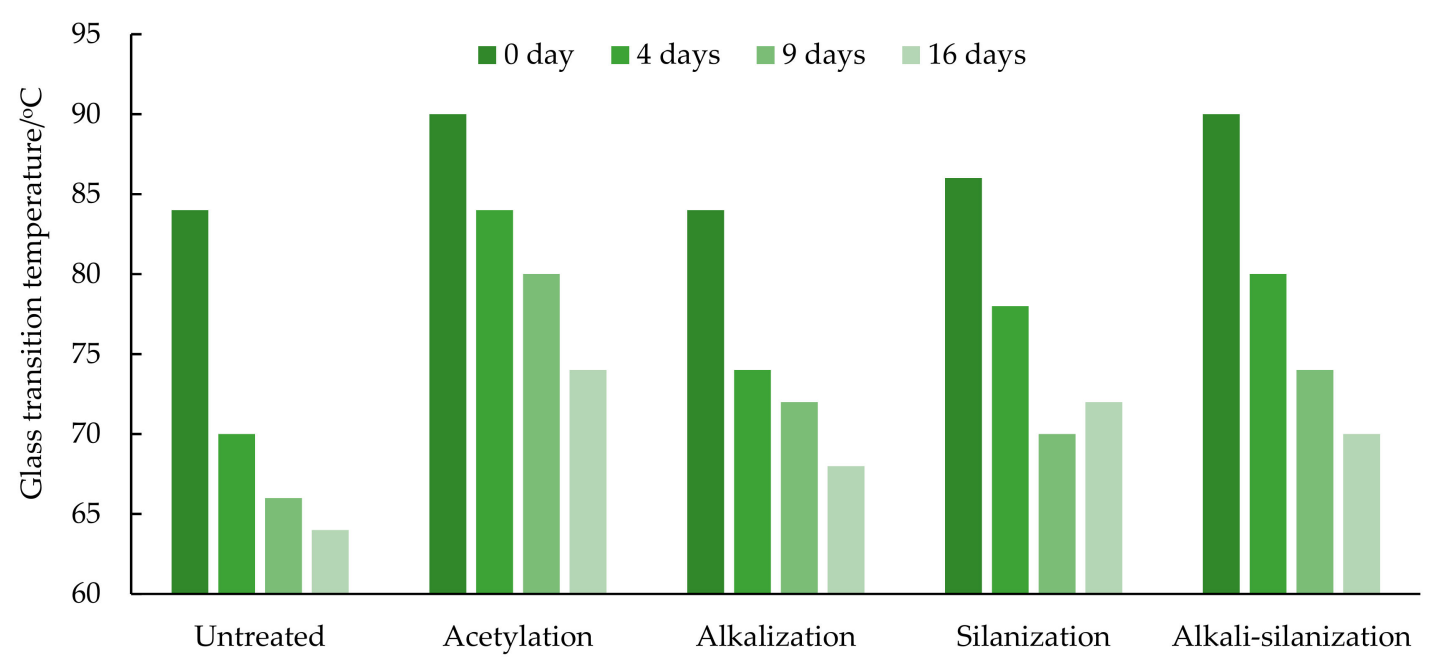

Figure 6. Glass transition temperature of FFRP.

\section{Discussion}

As shown in Figure 2 and Table 1, the weight increment percentage $M_{t}$ of FFRP increases significantly after being exposed to a hydrothermal environment, and the increasing rate slows down with the increase of aging time. The diffusion coefficient and maximum weight increment percentage of all treated specimens are lower than the reference specimen. The difference in hygroscopicity indicates that surface treatment helps slow down the rate of moisture diffusion process $[34,35]$. Compared with the reference specimen, the diffusion coefficient of alkalization, silanization, acetylation, and alkali-silanization treated FFRP decreases by $30.1 \%, 43.7 \%, 47.3 \%, 45.8 \%$, and the maximum weight increment percentage $M_{m}$ decreases by $17.4 \%, 27.7 \%, 42.2 \%, 32.0 \%$, respectively.

The storage modulus curve of FFRP can be divided into two regions: the glassy region (temperature below glass transition temperature $T_{g}$ ), and the rubbery region (temperature above $T_{g}$ ), as shown in Figure 3. In the glassy region, the components in FFRP are highly immobile, therefore the storage modulus of FFRP is high. In the rubbery region, the components of the FFRP are more mobile and lose their close packing arrangement, therefore the storage modulus decreases with temperature [36]. The storage modulus of FFRP in both the glassy region and the rubbery region decreases significantly after hydrothermal aging. This is due to the degradation of epoxy, fiber and the fiber/epoxy interface. As shown in Figure 4, moisture has significant influence on the storage modulus of FFRP. Moisture absorption increases rapidly in the initial stage, and the storage modulus decreases rapidly. With the increase of hydrothermal aging time, the moisture content tends to be saturated, and the decline rate of storage modulus also slows down. For example, after 16 days of hygrothermal aging, the storage modulus of the reference specimen at $30{ }^{\circ} \mathrm{C}\left(<T_{g}\right)$ decreases by $51.5 \%, 63.3 \%$ and $75.6 \%$, and the storage modulus of the reference specimen at $100{ }^{\circ} \mathrm{C}\left(>T_{g}\right)$ decreases by $251.0 \%, 201.8 \%$, and $290.0 \%$, respectively. In addition, the slope of the transition zone of the storage modulus curve decreases with hydrothermal aging time.

After chemical treatment, the storage modulus of FFRP is significantly improved in both the glassy and the rubbery region. For example, after 16 days of hydrothermal aging, compared with the reference specimen, the storage modulus of the acetylation, alkalization, silanization, and alkali-silanization treated specimens at $30{ }^{\circ} \mathrm{C}$ increased by $49.4 \%, 22.6 \%, 19.4 \%$, and $37.1 \%$; the storage modulus at $100{ }^{\circ} \mathrm{C}\left(>T_{g}\right)$ increases by $197.1 \%, 61.0 \%, 33.8 \%$, and $124.5 \%$, respectively. Firstly, chemical treatment contributes to reducing the water uptake of the FFRP. Secondly, chemical treatment helps create a stronger bond interface between fiber and matrix, which limits the movement of the molecules. Therefore, the storage modulus of FFRP is improved.

Damping represents the dissipation of energy in FFRP under cyclic loading. The loss factor is measured as the tangent of the phase angle or the ratio of loss modulus to storage modulus. As shown 
in Figures 3 and 5, the value of the loss factor increases with hygrothermal aging time and moisture content in FFRP. For example, after 4, 9 and 16 days of hygrothermal aging, the peak value of the loss factor of the reference specimen increase by $50.4 \%, 57.5 \%$, and $61.1 \%$, respectively. It is also noticed that after hydrothermal aging, the peak point of the loss factor shifts to lower temperatures, and the curve becomes wider. Firstly, hygrothermal aging causes disorganization of flax microfibrils network and the plasticization of matrix. Secondly, water weakens the van der Waals force of the flax/matrix interface and causes the hydrolysis of chemical bonds at the interface, which leads to interfacial debonding. Previous studies [37-40] have shown that FRP with a poor fiber/matrix interface tends to dissipate more energy than FRP with good interfacial adhesion, therefore, poor interface adhesion leads to a larger loss factor.

The peak value of loss factors of treated FFRP are lower than the reference specimen. After 16 days of hygrothermal aging, the peak value of the loss factor decreases by $36.7 \%, 15.6 \%, 23.3 \%$, and $33.9 \%$ after acetylation, alkalization, silanization and alkali-silanization. The loss factor of fiber reinforced composites mainly depends on matrix, fiber volume ratio and the fiber/matrix interface [37,41,42]. Since all specimens have the same matrix and fiber volume ratio, acetylation and alkali-silanization treated specimens exhibit the lowest peak value of loss factor, which indicates that flax fiber after these treatments show better adhesion with the epoxy. As mentioned in the introduction, acetylation and alkalization help to clean the impurities and pollutants, and promise a rougher fiber surface to provide mechanical interlocking between fiber and matrix. Therefore, flax fiber hinders the mobility of polymer chains due to the enhancement of the fiber/matrix interface and the loss factor is reduced.

As shown in Figure 6, a significant decrease in the glass transition temperature of FFRP is observed after hygrothermal aging. For example, the glass transition temperature of the reference specimen decreases by $20.0 \%, 27.3 \%, 31.3 \%$ after 4 days, 9 days and 16 days of hygrothermal aging. Moisture has an adverse effect on the molecular structure of epoxy. Water can loosen the molecular chains of epoxy, increase the molecular spacing, and enhance the activity of chemical groups, which results in the decrease of glass transition temperature [43]. Water also reduces the intermolecular hydrogen bonds between flax fiber and epoxy by creating intermolecular hydrogen bonds between the cellulose molecules and water molecules. At first, water absorbs quickly, which leads to a significant drop in the glass temperature of FFRP. With the increase of hygrothermal aging time, the moisture content of FFRP tends to be saturated and the decrease rate of the glass temperature slows down.

An increase of the glass transition temperature of FFRP is observed after surface treatment. Compared with reference specimen, the value of the glass transition temperature increases by $15.6 \%$, $6.3 \%, 12.5 \%, 9.4 \%$ after being treated by acetylation, alkalization, silanization and alkali-silanization, respectively. It can be inferred that this is a manifestation of structural enhancement after surface treatment. Systems with more restrictions and greater enhancements tend to exhibit higher glass transition temperatures [44]. After chemical treatment, the flax fiber surface is cleaner and rougher. The change of surface morphology leads to larger contact area between the fibers and epoxy and a stronger fiber/matrix bond interface, which limits the molecular mobility of FFRP when exposed to elevated temperatures.

\section{Conclusions}

Previous research shows that the static mechanical properties and water resistance of FFRP can be improved after surface treatment. The tests carried out in this paper show that surface treatments are also critical in improving the damping properties of FFRP under hydrothermal conditions.

Test results show that the storage modulus and glass transition temperature of FFRP decrease significantly with hygrothermal aging time and moisture content. The decreasing rate slows down with the increase of aging time. In addition, an increase of the peak value of the loss factor is observed. After 16 days of hygrothermal aging, the peak value of the loss factor of the reference specimen increases by $61.1 \%$, and the glass transition temperature decreases by $31.3 \%$. This is mainly due to the plasticization of epoxy resin and the degradation of the fiber/matrix interface. 
After surface treatment, the water uptake of FFRP is reduced. The diffusion coefficient of the FFRP after alkalization, silanization, acetylation, and alkali-silanization decreases by $30.1 \%, 43.7 \%, 47.3 \%$, $45.8 \%$, respectively. Compared with reference specimen, the storage modulus and glass transition temperature of the treated specimen are higher, and the peak value of the loss factor is lower. The acetylation treated FFRP exhibits excellent damping performance in all dynamic properties.

Environmental conditions are one of the most critical factors affecting the service life of FRP. Therefore, it is necessary to consider the effects of environmental degradation on the FFRP when evaluating the overall performance of the FRP structures. The test carried out in this paper may help increase the durability database and achieve a more fundamental understanding of the degradation mechanism of FFRP. The obtained relationships between moisture content and damping properties may have potential applications in life predictions of FFRP structures.

Author Contributions: X.W. designed and performed the experiments under M.P.'s guidance. X.W. wrote the manuscript and M.P. revised the article.

Funding: This work is supported by the Ministry of Education, Youth and Sports of the Czech Republic and the European Union (European Structural and Investment Funds-Operational Programme Research, Development and Education) in the frames of the project "Modular platform for autonomous chassis of specialized electric vehicles for freight and equipment transportation", Reg. No. CZ.02.1.01/0.0/0.0/16_025/0007293.

Conflicts of Interest: The authors declare no conflict of interest.

\section{References}

1. Yan, L.; Chouw, N.; Jayaraman, K. Flax fibre and its composites-A review. Compos. Part B 2014, 56, $296-317$. [CrossRef]

2. Begum, K.; Islam, M.A. Natural Fiber as a substitute to Synthetic Fiber in Polymer Composites: A Review. Res. J. Eng. Sci. 2013, 2, 46-53.

3. Zhang, Y.; Li, Y.; Ma, H.; Yu, T. Tensile and interfacial properties of unidirectional flax/glass fiber reinforced hybrid composites. Compos. Sci. Technol. 2013, 88, 172-177. [CrossRef]

4. Zhu, J.; Zhu, H.; Njuguna, J.; Abhyankar, H. Recent development of flax fibres and their reinforced composites based on different polymeric matrices. Materials 2013, 6, 5171-5198. [CrossRef] [PubMed]

5. Dittenber, D.B.; Gangarao, H.V.S. Critical review of recent publications on use of natural composites in infrastructure. Compos. Part A Appl. Sci. Manuf. 2012, 43, 1419-1429. [CrossRef]

6. Shahzad, A. Hemp fiber and its composites-A review. J. Compos. Mater. 2012, 46, 973-986. [CrossRef]

7. Saidane, E.H.; Scida, D.; Assarar, M.; Ayad, R. Assessment of 3D moisture diffusion parameters on flax/epoxy composites. Compos. Part A Appl. Sci. Manuf. 2016, 80, 53-60. [CrossRef]

8. Stamboulis, A.; Baillie, C.A.; Peijs, T. Effects of environmental conditions on mechanical and physical properties of flax fibers. Compos. Part A Appl. Sci. Manuf. 2001, 32, 1105-1115. [CrossRef]

9. Hill, C.A.S.; Norton, A.; Newman, G. The water vapor sorption behavior of natural fibers. J. Appl. Polym. Sci. 2010, 112, 1524-1537. [CrossRef]

10. Chen, H.; Miao, M.; Xin, D. Influence of moisture absorption on the interfacial strength of bamboo/vinyl ester composites. Compos. Part A Appl. Sci. Manuf. 2009, 40, 2013-2019. [CrossRef]

11. Zakaria, S.; Kok, P.L. Polystyrene-benzoylated EFB reinforced composites. J. Macromol. Sci. Part D Rev. Polym. Process. 2002, 41, 951-962. [CrossRef]

12. Azwa, Z.N.; Yousif, B.F.; Manalo, A.C.; Karunasena, W. A review on the degradability of polymeric composites based on natural fibres. Mater. Des. 2013, 47, 424-442. [CrossRef]

13. Li, Y.; Xue, B. Hydrothermal ageing mechanisms of unidirectional flax fabric reinforced epoxy composites. Polym. Degrad. Stab. 2016, 126, 144-158. [CrossRef]

14. Assarar, M.; Scida, D.; Mahi, A.E.; Poilâne, C.; Ayad, R. Influence of water ageing on mechanical properties and damage events of two reinforced composite materials: Flax-fibres and glass-fibres. Mater. Des. 2011, 32 , 788-795. [CrossRef]

15. Mak, K.; Fam, A.; Macdougall, C. The effects of long term exposure of flax fiber reinforced polymer to salt solution at high temperature on tensile properties. Polym. Compos. 2016, 37, 3234-3244. [CrossRef] 
16. Ventura, H.; Claramunt, J.; Rodríguez-Pérez, M.A.; Ardanuy, M. Effects of hydrothermal aging on the water uptake and tensile properties of PHB/flax fabric biocomposites. Polym. Degrad. Stab. 2017, 142, 129-138. [CrossRef]

17. Scida, D.; Assarar, M.; Poilâne, C.; Ayad, R. Influence of hygrothermal ageing on the damage mechanisms of flax-fibre reinforced epoxy composite. Compos. Part B 2013, 48, 51-58. [CrossRef]

18. Thuault, A.; Eve, S.; Blond, D.; Breard, J.; Gomina, M. Effects of the hygrothermal environment on the mechanical properties of flax fibres. J. Compos. Mater. 2014, 48, 1699-1707. [CrossRef]

19. Yan, L.; Chow, N.; Yuan, X. Improving the mechanical properties of natural fibre fabric reinforced epoxy composites by alkali treatment. J. Reinf. Plast. Compos. 2012, 31, 425-437. [CrossRef]

20. Amiri, A.; Ulven, C.; Huo, S. Effect of chemical treatment of flax fiber and resin manipulation on service life of their composites using time-temperature superposition. Polymers 2015, 7, 1965-1978. [CrossRef]

21. Bledzki, A.K.; Mamun, A.A.; Lucka-Gabor, M.; Gutowski, V.S. The effects of acetylation on properties of flax fibre and its polypropylene composites. Express Polym. Lett. 2008, 2, 413-422. [CrossRef]

22. Bledzki, A.K.; Lucka, M.; Mamun, A.A.; Michalski, J. Biological and electrical resistance of acetylated flax fibre reinforced polypropylene composites. Bioresources 2008, 4, 111-125.

23. Xie, Y.; Hill, C.A.S.; Xiao, Z.; Militz, H.; Mai, C. Silane coupling agents used for natural fiber/polymer composites: A review. Compos. Part A 2010, 41, 806-819. [CrossRef]

24. Georgiopoulosa, P.; Kontoua, E.; Georgousisa, G. Effect of silane treatment loading on the flexural properties of PLA/flax unidirectional composites. Compos. Commun. 2018, 10, 6-10. [CrossRef]

25. Amidi, S.; Wang, J. Engineering FRP-to-concrete bonded joints for better durability. In Proceedings of the American Society for Composites, University of California San Diego, La Jolla, CA, USA, 8-10 September 2014. Vol. Twenty-ninth Technical Conference on Composite Materials.

26. Chandra, R.; Singh, S.; Gupta, K. Experimental evaluation of damping of fiber-reinforced composites. J. Compos. Technol. Res. 2003, 25, 96-107.

27. Duc, F.; Bourban, P.E.; Plummer, C.J.G.; Månson, J.-A.E. Damping of thermoset and thermoplastic flax fibre composites. Compos. Part A Appl. Sci. Manuf. 2014, 64, 115-123. [CrossRef]

28. Cheour, K.; Assarar, M.; Scida, D.; Ayad, R.; Gong, X.-L. Effect of water ageing on the mechanical and damping properties of flax-fibre reinforced composite materials. Compos. Struct. 2016, 152, 259-266. [CrossRef]

29. Berges, M.; Léger, R.; Placet, V.; Person, V.; Corn, S.; Gabrion, X.; Rousseau, J.; Ramasso, E.; Ienny, P.; Fontaine, S. Influence of moisture uptake on the static, cyclic and dynamic behaviour of unidirectional flax fibre-reinforced epoxy laminates. Compos. Part A Appl. Sci. Manuf. 2016, 88, 165-177. [CrossRef]

30. Tayfun, U.; Dogan, M.; Bayramli, E. Influence of surface modifications of flax fiber on mechanical and flow properties of thermoplastic polyurethane based eco-composites. J. Nat. Fibers 2016, 13, 309-320. [CrossRef]

31. China National Standardization Management Committee; General Administration of Quality Supervision, Inspection and Quarantine of the People's Republic of China. Test Method for Aging Properties of Glass Fiber Reinforced Plastics; China Building Industry Press: Beijing, China, 2008; pp. 1-13.

32. Luo, H.L.; Lian, J.J.; Wan, Y.Z.; Huang, Y.; Wang, Y.L.; Jiang, H.J. Moisture absorption in VARTMed three-dimensional braided carbon-epoxy composites with different interface conditions. Mater. Sci. Eng. A 2006, 425, 70-77. [CrossRef]

33. Karbhari, V.M.; Xian, G. Hygrothermal effects on high pultruded unidirectional carbon/epoxy composites: Moisture Uptake. Compos. Part B Eng. 2009, 40, 41-49. [CrossRef]

34. Georgiopoulos, P.; Christopoulos, A.; Koutsoumpis, S.; Kontou, E. The effect of surface treatment on the performance of flax/biodegradable composites. Compos. Part B Eng. 2016, 106, 88-98. [CrossRef]

35. Anna, D.K.F.; Balan, A.; Bin, H.; Xian, G.; Thomas, S. Effect of surface modification of jute fiber on the mechanical properties and durability of jute fiber-reinforced epoxy composites. Polym. Compos. 2018, 1-10.

36. Jacob, M.; Francis, B.; Thomas, S.; Varughese, K.T. Dynamical mechanical analysis of sisal/oil palm hybrid fiber-reinforced natural rubber composites. Polym. Compos. 2006, 27, 671-680. [CrossRef]

37. Shanmugam, D.; Thiruchitrambalam, M. Static and dynamic mechanical properties of alkali treated unidirectional continuous Palmyra Palm Leaf Stalk Fiber/jute fiber reinforced hybrid polyester composites. Mater. Des. 2013, 50, 533-542. [CrossRef]

38. Pothan, L.A.; Oommen, Z.; Thomas, S. Dynamic mechanical analysis of banana fiber reinforced polyester composites. Compos. Sci. Technol. 2003, 63, 283-293. [CrossRef] 
39. Afaghi-Khatibi, A.; Mai, Y.-W. Characterisation of fibre/matrix interfacial degradation under cyclic fatigue loading using dynamic mechanical analysis. Compos. Part A Appl. Sci. Manuf. 2002, 33, 1585-1592. [CrossRef]

40. Fiore, V.; Scalici, T.; Vitale, G.; Valenza, A. Static and dynamic mechanical properties of Arundo Donax fillers-epoxy composites. Mater. Des. 2014, 57, 456-464. [CrossRef]

41. Fiore, V.; Bella, G.D.; Valenza, A. The effect of alkaline treatment on mechanical properties of kenaf fibers and their epoxy composites. Compos. Part B Eng. 2015, 68, 14-21. [CrossRef]

42. Chandra, R.; Singh, S.P.; Gupta, K. Damping studies in fiber-reinforced composites-A review. Compos. Struct. 1999, 46, 41-51. [CrossRef]

43. Gao, Y. Study on Environment Behavior and Aging Mechanism of Epoxy Adhesive; Beijing University of Chemical Technology: Beijing, China, 2006.

44. Júnior, J.H.S.A.; Júnior, H.L.O.; Amico, S.C.; Amado, F.D.R. Study of hybrid intralaminate curaua/glass composites. Mater. Des. 2012, 42, 111-117. [CrossRef]

(C) 2019 by the authors. Licensee MDPI, Basel, Switzerland. This article is an open access article distributed under the terms and conditions of the Creative Commons Attribution (CC BY) license (http://creativecommons.org/licenses/by/4.0/). 